\title{
Planting roots: Urban agriculture for senior immigrants
}

\author{
Mary Beckie ${ }^{a}$ \\ Faculty of Extension, University of Alberta \\ Eva Bogdan \\ Project Officer, Community Futures Alberta
}

Submitted 22 June 2010 / Accepted 26 October 2010/ Published online November 2010

Citation: Beckie, M. and Bogdan, E. (2010, November). Planting roots: Urban agriculture for senior immigrants. Journal of Agriculture, Food Systems, and Community Development, 1(2): 77-89. doi:10.5304/jafscd.2010.012.004

Copyright (C) 2010 by New Leaf Associates, Inc.

\begin{abstract}
In 2007, a community-university pilot project was launched in Edmonton, Alberta, Canada, to train and involve senior immigrants in Small Plot Intensive (SPIN)-Farming, a commercial approach to urban agriculture. Immigrants represent a significant proportion of the senior population in urban Canada, but their adaptation and integration into Canadian society can be extremely challenging. We hypothesized that involvement in commercial urban agriculture could help to address some of the economic as well as social issues they face.

Evaluation of the project's impacts in year one was based primarily on qualitative interviews with participants and community organizers following the training and implementation phases. Although limited income was generated as a result of modifications to the SPIN-Farming approach, this research suggests that involvement in commercial urban agriculture can contribute to the integration of senior immigrants into Canadian society, while
\end{abstract}

\footnotetext{
${ }^{a}$ corresponding author: Assistant Professor, Faculty of Extension, University of Alberta, 10230 Jasper Avenue, Edmonton, Alberta, T5J 4P6 Canada; mary.beckie@ualberta.ca
}

also contributing to the evolution of local food systems and more inclusive communities.

\section{Keywords}

senior immigrants, urban agriculture, SPINFarming, social enterprise, community-university partnership

\section{Introduction and Background}

\section{Seniors, Immigrants and Urban Agriculture}

The past half century has seen a major shift in the world's population from rural areas to urban centers, and increasing migration from Southern to Northern cities (UN-Habitat, 2004). In Canada, recent census data indicates that 6.2 million people, or $19.8 \%$ of the total population, are immigrants, ${ }^{1}$ the highest proportion in 75 years (Statistics Canada, 2006). One quarter of the current immigrant population is aged 65 and older, and $80 \%$ of

\footnotetext{
${ }^{1}$ According to Statistics Canada, an immigrant is defined as a person who is, or has been, a landed immigrant in Canada. A landed immigrant is a person who has been granted the right to live in Canada permanently by immigration authorities. It should be noted that immigrant status is distinct from refugee status.
} 
these seniors ${ }^{2}$ live in census metropolitan areas (Statistics Canada, 2006).

The integration of senior immigrants into Canadian life, and their overall health and well-being, is influenced by a number of socio-economic and environmental circumstances, such as economic security, social inclusion and exclusion, food security, and housing (Durst, 2005). For recent senior immigrants, financial security can be a pressing concern as eligibility for the Canada pension plan is dependent upon having lived in Canada for 10 years or more (Durst, 2005; Service Canada, 2010). This and other variables identified as social determinants of health ${ }^{3}$ are viewed as having an equal if not more important impact on an individual's health than medical care and personal health behaviors (Raphael, 2004; Public Health Agency of Canada, 2010).

Urban agriculture, whether focused on household consumption or commercial enterprise, has proven to be an effective way for many minority groups to become integrated into the socio-economic fabric of the cultures and countries to which they immigrate (Hannah \& Oh, 2000; Mougeot, 2006, Redwood, 2009; Valtonen, 2004). In Montreal, Italian and Portuguese immigrants were instrumental in establishing the first community gardens during the 1970s, and the city's community garden program continues to have a strong multicultural presence (Cosgrove, 2010; Mougeot, 2006). Several other urban agriculture programs and projects involving immigrants are currently underway across North America, such as the Field to Table Urban Agriculture project run by Food Share in Toronto (www.foodshare.net), Cob Connection in Chicago (www.cobconnection.org), and Heifer International's programs in various cities across the United States (www.heifer.org).

On a broader social scale, there is increasing evidence that urban agriculture has positive impacts

\footnotetext{
2 The Canadian government defines seniors as individuals 65 years of age and older.

${ }^{3}$ http://www.phac-aspc.gc.ca/ph-sp/determinants/indexeng.php
}

on individual and community health and wellbeing. In a summary of results from two decades of research on urban agriculture, Canada's International Development Research Council (IDRC) identifies several benefits of urban agriculture, including improved access to fresh and nutritious food, reduced food costs, physical exercise, therapy and recreation, income generation, reduced food miles, ${ }^{4}$ urban greening, ${ }^{5}$ and community capacitybuilding (Mougeot, 2006). Increased social engagement experienced through urban agriculture and direct marketing has been shown to positively correlate with personal attention to health care and wellness, and provides opportunities for relationship-building and information exchange (Bellows, Brown, \& Smit, 2003).

A number of studies have investigated the role of gardening in the health and well-being of older adults. Milligan, Gatrell, and Bingley (2004) found that gardening offers isolated seniors a reason to leave their households and engage in the wider landscape. Furthermore, they report that communal gardening can create an inclusive space in which seniors "benefit from gardening activity in a mutually supportive environment that combats social isolation and contributes to the development of their social networks" (2004, p. 1781). Working with soil and plants improves seniors' mental health and personal wellness by contributing to a sense of achievement, satisfaction, and aesthetic pleasure, and increased confidence and self-esteem (Brown, Allen, Dwozan, Mercer, \& Warren, 2004; Milligan et al., 2004; Patel, 1991). Gardening has also been shown to induce relaxation, and reduce fear, anger, and stress in older adults, which in turn affects physical health (Milligan et al., 2004).

Despite significant evidence of the socio-economic benefits of urban agriculture for immigrants, and

\footnotetext{
${ }^{4}$ Food miles is a term that refers to the distance food is transported from the site of production to the site of consumption.

${ }^{5}$ Urban green space is a term that refers to public and private spaces in urban areas that are primarily covered by vegetation. Increasing urban green spaces, referred to as urban greening, is seen to play a prominent role in enhancing the sustainability and livability of a city.
} 
other studies reporting on the positive impacts of gardening on seniors' health and well-being, the linking of senior immigrants with commercial urban agriculture has not been previously reported. The research described in this paper is, to the best of our knowledge, the first investigation of this kind. We set out to explore if involvement with Small Plot Intensive Farming (SPIN-Farming), a commercial approach to urban agriculture, could contribute to immigrant seniors' adaptation and integration into urban life in Canada, and improve their overall health and well-being.

\section{SPIN-Farming}

Small Plot Intensive Farming, also known as SPINFarming, is a commercial approach to urban agriculture developed by Wally Satzewich and Gail Vandersteen, two market gardeners based in Saskatoon, Saskatchewan, Canada. This method integrates relay planting, ${ }^{6}$ to maximize harvest volume as well as economic gain, and organic farming methods, ${ }^{7}$ which reduce reliance on external inputs by eliminating the use of synthetically manufactured fertilizers and pesticides. SPIN-Farming requires moderate start-up costs and low operating and overhead costs, and has been shown to generate relatively high levels of income from a subacre land base (Satzewich \& Christensen, 2005; Urban Partners, 2007). This approach also allows for flexibility in the scope and scale of the production system, as well as flexibility in land-use arrangements. For example, Satzewich and Vandersteen run a multisite operation from a number of rented backyards in Saskatoon, whereas a single-site SPIN initiative was developed in Philadelphia on a half-acre of land owned by that city's Water Works Department. A detailed manual describing the SPIN method has been developed (Satzewich \& Christensen, 2005) and can be

\footnotetext{
${ }^{6}$ The SPIN relay planting method involves the reseeding of the planting bed following crop harvest. For short-term crops, such as lettuce and spinach, it is possible to harvest two to three crops per season (www.spinfarming.com).

${ }^{7}$ Organic certification is considered optional in the SPINFarming approach, but organic methods are incorporated to reduce operating costs associated with agrochemical use as well as to foster production systems that are more ecologically, economically, and socially sustainable.
}

ordered through the SPIN website (www.spinfarming.com). Over the past five years, Satzewich and Vandersteen have delivered several SPIN training workshops throughout North America. In addition to the SPIN-Farming manual, an economic analysis of the five-year SPIN initiative in Philadelphia is available on the SPIN website (Urban Partners, 2007). Thus, as a well developed, tested, and accessible method, SPINFarming was identified as a plausible way to introduce senior immigrants in Edmonton to commercial urban agriculture.

\section{Research Purpose, Methodology, and Methods}

Senior immigrants represent a vulnerable and poorly understood, but significant, segment of Canadian society (Durst, 2005). As many senior immigrants living in Edmonton were known to come from rural and farming backgrounds, it was hypothesized that providing them with an opportunity to become involved in a commercial approach to urban agriculture could help to address the economic, social, and health challenges they face. To test this hypothesis, we investigated the impacts resulting from senior immigrants' involvement in the pilot year of the "Urban Agriculture for Senior Immigrants" project. This pilot project was initiated in Edmonton, Alberta, in 2007 through a university-community partnership involving the Seniors' Association of Greater Edmonton $(\mathrm{SAGE})^{8}$ serving as the overall coordinating agency, the Multicultural Health Brokers Co-operative $(\mathrm{MCHB})^{9}$ providing connections to senior immigrants from various ethnic communi-

\footnotetext{
${ }^{8}$ Seniors' Association of Greater Edmonton (SAGE) is a nonprofit organization that provides services to older adults (55 and over) and their families, including information and referral, social services, advocacy, housing, help in applying for court-appointed guardianship, relocation services, and homemaintenance assistance. It also offers health, lifestyle, social, and recreation programs.

${ }^{9}$ Multicultural Health Brokers Co-operative (MCHB) is a registered worker's cooperative with members from immigrant and refugee communities in Edmonton. For the past 10 years, it has been providing culturally and linguistically relevant public health support to immigrant and refugee families in a number of areas, such as family relationships, housing, education, economics, and food security.
} 
ties and serving as interpreters during the project, and members of the Faculty of Extension ${ }^{10}$ at the University of Alberta carrying out research during the pilot year of the project.

We utilized exploratory (Stebbins, 2001) and qualitative case study (Yin, 2009) approaches to investigate the first year of the pilot project. Issue identification, analysis of themes, and evaluation and integration of information were based on review of documentary data (academic and popular press) as well as narrative data gathered from qualitative interviews, and researchers' observations. Two sets of interviews $(n=26)$ were conducted, at the end of the workshop and after final harvest, with seniors, the gardening coordinator, and representatives from SAGE and MCHB. SPIN trainers were interviewed once, following completion of the workshop. Interviews ranged from 60 to 90 minutes, and were recorded and transcribed verbatim. Interviews with senior immigrants included interpretation by a $\mathrm{MCHB}$ representative where necessary. Interviews were semistructured, guided by a list of predetermined topics and questions. Participants were encouraged to speak freely on topics they identified as relevant, however. Grounded theory was used as a framework for data analysis (Charmaz, 2000; Strauss \& Corbin, 1998), as issues and themes were drawn from the data. Photographs were used to document the project, to illustrate the emergence of specific themes from narrative and documentary data, and also as ways to disseminate knowledge gained in this research.

Preliminary discussions about the feasibility of this project took place during the summer of 2006 with representatives from the three agencies. Informal inquiries with seniors of different ethnic communities indicated there was sufficient interest for

\footnotetext{
${ }^{10}$ The Faculty of Extension works collaboratively with other faculties and educational institutions, professional and community associations, business organizations, and public agencies. It "promotes responsive university-community engagement through a wide range of innovative, learningcentered programs, and includes inquiry (research and experimentation), and practice (services, products, and events)" (Rajwani, 2009).
}

project planning to proceed. By early January 2007, both project and research funding had been secured. The pilot was divided into two phases. Phase one (January-February 2007) involved participant recruitment followed by a three-day SPIN training workshop. Phase two (MarchSeptember 2007) involved preparation for and implementation of SPIN-Farming. The objectives for the workshop were to provide effective knowledge transfer on SPIN-Farming; to provide opportunities for sharing knowledge among the participants; and to provide an enjoyable learning experience that would motivate the seniors to continue with phase two. The objective for phase two was to provide opportunities for participants to improve their quality of life by addressing the following social determinants of health: income and social status, personal health (physical and mental) practices and coping skills, and food security and nutrition (Public Health Agency of Canada, 2010).

A SPIN-Farming workshop was conducted by Satzewich and Vandersteen over two and a half days in late February 2007 at SAGE in downtown Edmonton. Senior immigrants, aged 55 years and older, ${ }^{11}$ were recruited by MCHB and SAGE from the various ethnic communities they work with. Recruitment was based on interest, self-assessed physical ability, and immigrant (versus refugee) status at the time of entry. Language interpretation was provided by MCHB brokers. The SPIN trainers developed the workshop to accommodate language translation by simplifying the context and pacing their presentation accordingly. They also relied extensively on visual aids (photographs on poster boards and as part of a PowerPoint presentation), and incorporated hands-on demonstrations of tools and equipment. Following the completion of the workshop, those seniors interested in taking part in phase two were identified and provided with additional information regarding the implementation phase over the next few months.

The project was structured as a social enterprise, with senior participants carrying out jobs according

${ }^{11}$ SAGE defines seniors as 55 years of age or older. 
to their interest and abilities, SAGE providing overall coordination, and MCHB brokers providing language support for the seniors, but to a lesser degree than during the workshop. A coordinator with extensive horticultural teaching experience was hired by SAGE to oversee development (securing the land base, purchasing seeds and tools, creating a work plan from seeding to harvest and marketing) and assist the seniors in the daily running of the project. Advertisements for land were placed in local newspapers and on social networking sites. The selection of the four gardening sites was based on plot size, access to water, and proximity to seniors' residences. First plantings took place in May, but plantings continued throughout the summer to maximize diversity, volume, and profits. The final harvest, at the end of September, signaled the end of phase two. Harvested fresh produce was taken home on a regular basis by the seniors and shared with their families and friends, with the coordinator selling the surplus during the summer through informal networks. The coordinator and some of the seniors operated a stall in early September at one farmers' market event in downtown Edmonton. The Korean seniors also sold bok choy and other ethnic vegetables to a small number of Korean restaurants in Edmonton.

\section{Results and Discussion}

\section{Participants Profiles, Motivations, and Concerns} Thirteen seniors (five males and eight females) from six different ethnic backgrounds (Argentinean, Bosnian, Chilean, Croatian, Korean, and Kurdish) took part in the SPIN training workshop and were involved in the preparation and seeding of the plots (see table 1). The age of participants ranged from 55 to 85 , but the highest proportion were in the 65-to-75 age category.

As the season progressed, eight of the original group of seniors (three males and five females) dropped out of the project, but the remaining five (two males and three females) participated on a regular basis. There were a variety of reasons provided by the seniors for withdrawing from the project, none of which stemmed from dissatisfac-

\section{Table 1: SPIN-Farming Workshop Participants}

\begin{tabular}{lcc}
\hline $\begin{array}{l}\text { Ethnic origin of } \\
\text { participants }\end{array}$ & $\begin{array}{c}\text { Number and gender } \\
\text { of participants }\end{array}$ & $\begin{array}{c}\text { Percentage } \\
\text { of total }\end{array}$ \\
\hline Korean & $5(4 \mathrm{f}, 1 \mathrm{~m})$ & 38.4 \\
Kurdish & $3(\mathrm{~m})$ & 23.1 \\
Bosnian & $2(1 \mathrm{f}, 1 \mathrm{~m})$ & 15.4 \\
Argentinean & $1(\mathrm{f})$ & 7.7 \\
Chilean & $1(\mathrm{f})$ & 7.7 \\
Croatian & $1(\mathrm{f})$ & 7.7 \\
\hline
\end{tabular}

tion with the project. For example, one couple had the opportunity to visit their son in the United States for most of the summer. One woman developed some serious health issues, and the 85year-old Korean man decided that there were enough people taking part and he felt he was too busy with other activities and responsibilities. Early in the growing season, five new seniors (one male and four females) joined the project. There were three additional seniors who participated on an irregular basis. As far as residency, five of the participants had been in Canada less than 10 years. Eight participants had lived in Canada for up to 29 years, but English language skills remained an issue, particularly for the Korean seniors, who can function fully in the well-established Korean community in Edmonton without having to speak English.

The seniors' prior experience with gardening and agriculture varied widely, from none at all to that of many years as large-scale field-crop farmers. The seniors identified various reasons for their interest in taking part in this project: "to have fresh vegetables," "to learn something and do something that makes me happy," "to have something to be busy with, I'm bored at home," "to be in contact with nature again," and "to socialize...We are not in our country, we don't have a lot of friends here...We need friends." A participant who had endured an ethnic war for three years in her homeland was drawn to the multicultural aspect of the project: "You know, it's in my memory, it was crazy back then [during the war]...this [project] is beautiful because all the different people come together and work together. That is first for me, then the 
vegetables to eat, and last money.” Interestingly, financial gain was not identified as a primary motivating factor by any of the seniors, despite $\mathrm{MCHB}$ indicating that many of the participants have very limited financial resources.

Following the training workshop, interviews with MCHB revealed that some seniors had concerns about using public transit to get to the garden sites. They were afraid of getting lost, given their limited knowledge of the city and weak English language skills. A few of the seniors said they did not want to be seen in public in their dirty work clothes, "carrying tools full of dirt," as it would be embarrassing. These concerns influenced the selection of four sites relatively close to the seniors' residences. Concerns were also expressed by some of the seniors' families who felt that their parent's involvement in a manual labor project was "exploitive," that they would be "working in the dirt for nothing." One senior's daughter asked her parent, "You worked hard all your life, why do you want to be a slave now?" Other family members were concerned that if their parents took part in this project, they wouldn't have the time or energy to help out with care of their grandchildren.

\section{Modified SPIN-Farming Approach}

It became apparent relatively early in the implementation phase that it was going to be difficult to achieve the intensity of production and subsequent economic return as outlined in the SPIN-Farming manual. There were several reasons for this. Securing the land base took longer than anticipated, which delayed seedbed preparation and seeding until the end of May, hence affecting the overall volume of produce. SPIN-Farming is a relatively intense approach, and the seniors were committed to working only two to three hours at a time, two to three days a week. Many of them did not have the physical capacity or the interest in working more often than that.

Soil at one of the sites was of poor quality and water was available but difficult to access at two of the sites. The coordinator's goal of implementing relay planting by growing and reseeding short-term maturing crops, such as leafy greens, was met with minimal enthusiasm. Many of the seniors wanted to grow vegetables they preferred to eat, and they also wanted to garden the way they were used to. As it was decided that first and foremost the seniors should have the opportunity to take fresh produce home, for personal consumption or for sharing with their families, the volume of vegetables remaining at the end of the week was insufficient to take to market, except toward the end of the summer when there was a higher volume of produce and flowers available.

A table summarizing the revenue and expenditures of the pilot year of the project is outlined below (table 2). The total net profit from sales during the summer was $C A N \$ 1,000$, of which $C A N \$ 300$ was made at the farmers' market in one day. The profit was divided equally among the participants, averaging approximately $\mathrm{CAN} \$ 100$ per senior. Some seniors said they did not feel right receiving the money because they thought it should be used for purchasing tools, seeds, and supplies for next year. One senior said on behalf of the others: "We did not contribute anything; then we get vegetables and

Table 2. Statement of Revenue and Expenditures for SPIN-Farming Pilot Project (January-October 2007) $^{\mathrm{a}}$

\begin{tabular}{|c|c|c|}
\hline Revenue & CAN\$ & CANS \\
\hline City of Edmonton & & $4,400.00$ \\
\hline Foundations & & $29,000.00$ \\
\hline In-kind contributions & & $2,900.00$ \\
\hline \multirow[t]{2}{*}{ Produce sales } & & $1,000.00$ \\
\hline & & $37,300.00$ \\
\hline
\end{tabular}

\begin{tabular}{|c|c|c|}
\hline Expenditures & & \\
\hline Advertising & 136.00 & \\
\hline Office rental & $1,000.00$ & \\
\hline Office equipment & 54.00 & \\
\hline Operations & $10,273.00$ & \\
\hline \multirow[t]{2}{*}{ Wages and benefits } & $24,837.00$ & \\
\hline & $36,300.00$ & \\
\hline Net Profit & & $1,000.00$ \\
\hline
\end{tabular}

a Data provided by SAGE. 
money, which is not fair." She further explained that she thought of the gardening more as volunteer work. The MCHB brokers conveyed to the researchers that despite the seniors' comments, the financial recompense, although very modest, was still beneficial to the seniors with limited financial resources. In addition, the seniors were able to save money that they would have normally spent on purchasing fresh produce, thus making this money available for them to spend in other ways.

When organizers were asked how they felt the project measured up in terms of the concept and the economic potential of SPIN-Farming, one had this response:

I'm kind of disappointed that it didn't really unfold as a pure SPIN project, because I think the concept is fabulous and we know that many of these people are in dire poverty. There is the potential to generate substantial income for them. But, that being said, it's up to them, and if that's not what they want to do, then who am I to say that's what they should be doing? It's not all about money; it's about a lot of other values...Do I think that SPIN is totally dead? No, I don't. I think it may reemerge with a certain number of people a year or two years down the road and we will come back to it and we will work it more intensively. I think it's still embedded within this project, even if it didn't fully meet that concept this year. We were very successful in spite of not adhering totally to SPIN but nor did we toss it out completely—so it's a modified SPIN.

The low economic output in the first year of this project could have been anticipated, given that most commercial enterprises take several years to make a profit, depending on a number of factors such as start-up costs, knowledge and skill development, changes in market demand, and other unforeseen challenges. The economic impact analysis of a five-year SPIN project in Philadelphia details the gradual improvements in economic performance that occurred from year to year (Urban Partners, 2007).
One of the advantages of the SPIN-Farming method is that it can be adapted to different circumstances, with outputs of produce, volume, and financial return varying according to scale and intensity of production. Thus, despite the low economic return in the first year of the project, the opportunity to scale up the profit-making aspect of this senior immigrant project was not lost. At the end of the growing season, the Korean seniors indicated their interests in scaling up their efforts the next year by doubling the size of their land base. Also, by seeding earlier and gardening more intensively, they planned to harvest four crops of Korean vegetables and expand their marketing portfolio by approaching additional Korean restaurants and grocery stores.

\section{Impacts on the Seniors, their Families, and the Wider Community}

Access to fresh and nutritious foods-for themselves, their families and friends - was of high importance to the seniors, and they were able to take home a variety of vegetables throughout the summer. The growing and sharing of produce created a sense of achievement and elevated their self esteem; according to MCHB, the seniors "felt happy that they could bring home vegetables" and contribute to their families. MCHB stated that many senior immigrants feel they are a burden to their families as they are not able to contribute financially. Thus, in addition to improving the seniors' access to fresh food, involvement in the project contributed to elevating their perception of social status within their families as well as their mental well-being. The seniors also shared food and seeds with each other, and exchanged recipes and telephone numbers. As one of the project organizers aptly commented, "There is nothing better than food to build community."

The seniors began to make their own decisions regarding crop selection during the plantings. The Kurdish participants, for example, were not interested in planting leafy greens, preferring tuberous vegetables, such as potatoes and carrots, which are more common to their diet and also have a long shelf life. The Korean participants initially grew what the coordinator had suggested, 
but after the first harvest replaced spinach and lettuce with sesame and bok choy. They were the only subgroup to develop their own market outlets through family, friends, and Korean restaurants. The Koreans' decision to grow their "own" vegetables and market ethnic vegetables to friends and restaurants was seen by an organizer as "one of the highlights" of the project.

\section{This is what I felt I really wanted to see. It's not our project, it's their project. They took it and went with it, they got the restaurant owners involved, they grew what they wanted to grow, they sold...That, to me, is really exciting.}

With four members, the Koreans formed the largest and seemingly most close-knit ethnic group. They were also very enthusiastic gardeners and produced the largest volume of produce. They would frequently have potluck picnic lunches at the garden, including the coordinator if she was present. They would also sing together while gardening. Despite these signs of harmony, a conflict arose between three of the members over the allocation of produce. The eldest felt entitled to the best vegetables, even though she worked the least (due to physical limitations), while the youngest had worked the hardest. In Korean culture, age influences social status and rights. The conflict was mediated by their MHCB broker and the project coordinator and was quickly resolved.

Many of the seniors spoke of the enjoyment and satisfaction they derived from watching the plants grow in the gardens, substantiating other research findings that aesthetic pleasure contributes to mental well-being (for example, see Milligan, Gatrell \& Bingley, 2004). The relaxation effect of gardening on the seniors was also observed by the coordinator, who said that gardening alongside one of the Korean participants was like "a meditation." One participant whose spouse had Alzheimer's commented, "This project, for me, is good, because of the stress [at home]. At the garden I forget my problems." The merging of physical and mental well-being experienced by one of the farmers is reflected in the following comment, as translated by one of the MHCB brokers: "Whenever he has time, he goes to the garden and does some work, and it makes him feel alive. It's a really fresh activity, and he can sweat sometimes and that clears his mind, so that was a good thing."

The project provided opportunities for a range of physical activities, from fine motor movements (e.g., cleaning, bagging the vegetables) to more strenuous movements (e.g., seeding, weeding, harvesting). Specialized labor-saving tools were available, but some of the seniors felt more comfortable using tools more familiar to them. In the garden site where soil conditions were not optimal, seeding and weeding were more laborintensive than anticipated. However, none of the seniors identified physical labor as a problem. The MHCB brokers and the coordinator did observe that the seniors' physical output was limited to two to four hours per day, every other day, for a maximum of three days per week, but varied according to their own schedules.

Organic farming methods were utilized in all the gardens, except for an initial and minimal use of synthetic fertilizer in the Korean garden before the coordinator was aware of it. No other agrochemicals were used; for example, a potato-bug infestation was managed manually with the help of a participant's four-year-old daughter. Food miles were low since the gardens were located close to the farmers' homes. The gardens also contributed to neighborhood greening, and the ethnic vegetables grown contributed to a broadening of the diversity of crops within Edmonton.

Not all the participants had previous gardening or agricultural experience, but this was not a barrier to their commitment to or benefits from the project. Individuals without previous experience said they "learned a lot from the project." For all the seniors, it was an opportunity to reconnect with nature; according to one, "It is to observe how plants grow - you plant it and then the next time when you come, you can see the difference. Each time you go there you see a result of your work." Learning also occurred around public transit use and increased English language vocabulary. One of the partici- 
pants made her own illustrated dictionary of the names of vegetables grown and other commonly used words, in both Korean and English. Even though English language skills were still limited by the end of the project, the coordinator and the MCHB brokers noted that the seniors' confidence to try and speak English had noticeably improved. They also overcame their fears of using public transit and expressed pride in having learned how to navigate the city's transit system.

A significant turning point in the seniors' involvement was reached when the project started receiving media attention and public interest. This made the seniors feel visible and valued, and it boosted their sense of pride. One of the organizers commented: "They wanted to talk to the press and tell their stories; it was really uplifting. They were clearly having fun and very proud of the work that they were doing." It was also a turning point in terms of acceptance of the seniors' involvement in the project by their families and communities. One MHBC broker said that when the seniors' pictures began to appear in the newspapers, the family members who had previously discouraged their parents' involvement now became very supportive of their continued involvement in the project.

Many immigrant seniors suffer a loss of identity after emigrating (Durst, Abu-Laban, MacLean, Ng, \& Northcutt, 2001). Durst et al. underline the importance of cultural connections to successful integration of immigrants. After establishing his garden, a Kurdish refugee exclaimed, "Come see the garden! We brought Kurdistan to Canada!” His statement illustrates one of the important successes of the project: in bringing the participants' pasts to the present, they created personal identity within a new landscape, making them feel more at home. Cultural connections were also developed during the workshop, as the seniors discussed familiar and unfamiliar vegetables, exchanged names of vegetables, compared tools, and shared gardening experiences. The coordinator, who is a Canadian and is very interested in other cultures and languages, was seen by some of the farmers as their bridge between Canadian culture and their own ethnic culture.
Seniors' participation in the project helped to reduce their social isolation; many of them said that they participated in the project in order to make new friends and build social networks. A son of one of the seniors said that if his father were not participating in the garden project, he would be "stuck at home, 24-7." One farmer said the garden project gave her a reason to "put on new and nice clothes to get out of the house" and tell people what she was doing. A few participants occasionally brought family members or friends to the garden. The farmers' market experience facilitated broader social exchange and other economic opportunities. One customer complimented a farmer on the scarf she was wearing and that she had made, and the customer requested that the senior make another for her to purchase. The Koreans were very enthusiastic market vendors, clapping their hands and smiling to get customers' attention. Not all enjoyed the experience, however; as one senior later commented, "I don't like to sell, but I like to grow."

\section{Conclusions}

The results of this research support findings from previous studies that have identified health benefits from gardening for older adults, as well as other research that has shown positive socio-economic impacts from urban agriculture for immigrants. In drawing together these topics, this research integrates knowledge emerging from these two areas of study and contributes new knowledge about the application of a novel commercial approach to urban agriculture by senior immigrants. The resulting impacts from the seniors' involvement in this initiative were analyzed using a social determinants of health framework, which also includes economic, social, and environmental factors in assessing health and well-being. Beyond the individual level, the effects of this project on the seniors' families and the wider community were also identified.

Participation in this pilot project generated a number of benefits for the seniors that extended well beyond nutrition and physical activity. By providing opportunities for the seniors to develop urban farming skills, and to grow fresh produce for personal consumption as well as for sharing with 
family and friends, this initiative contributed to individual learning and capacity-building, and feelings of self-worth. By creating opportunities for senior immigrants to develop and strengthen ties with both host and ethnic communities, social and cultural competencies were expanded, and their visibility and acknowledgement within the community increased, creating a deeper sense of acceptance and belonging. Willingness and confidence to engage with others outside of their ethnic community was observed to increase as the project progressed, which contributed to greater independence and mobility for the seniors within the urban landscape. Collaborative decision-making and entrepreneurship were also demonstrated, in the field and in the marketplace, particularly by the Korean seniors.

As relationships began to form and strengthen among the participants and the organizers, links to other social networks, such as those focused on food security, local food, ethnicity, and aging, began to emerge. There were also connections to and positive responses from the general public throughout the pilot year, beginning with the overwhelming number of backyards and commercial vacant lots offered for use during the project, to the strong interest and support for the project expressed at the farmers' market booth. There was significant media interest in the project, with articles in local newspapers as well as coverage on local television and radio stations. This public recognition influenced the shift in attitude and support by the seniors' family members.

The environmental impacts associated with this project were minimal given the scale of the operation, but can be considered positive in contrast with a conventional industrialized agricultural system. The project was not a major contributor to greenhouse gas emissions, as fossil fuel use was low due to reduced food miles, the use of public transit by the seniors, and the negligible use of agrochemicals. The seniors' gardens also contributed to neighborhood greening. The production of ethnic vegetables and heritage varieties contributed to a greater diversity of food crops grown within Edmonton, which contributed to development of the local food system.

The project was not without its challenges and limitations, however. Income generation was low compared to the figures outlined in the SPINFarming manual. A number of factors influenced this outcome. First, though the project had a commercial focus, economic gain was not the primary goal of the seniors, whereas social and health criteria were. Second, their physical capacity and other external commitments influenced the amount of time they were willing to dedicate to the project. Third, the overall volume of harvest from the project was impacted by the delay in initial seeding, a result of the unanticipated length of time it took to identify and acquire suitable garden sites. Fourth, the amount of produce available for sale was relatively low throughout most of the summer due to the priority given to the seniors' and their families' consumptive needs. Finally, changes made by the seniors to the selection of vegetable crops grown, while being more compatible with their ethnic and cultural preferences, did alter relay planting plans and schedules and subsequently impacted the volume and timing of harvest.

Despite the modest economic performance of the first year of the project, the role of SPIN-Farming in this initiative was assessed by the organizers as being "absolutely important—a catalyst" that launched the project and also provided an ongoing structure and framework. Although the seniors participating in the pilot year were not able and/or interested in achieving the intensity of production and marketing that can be accomplished using the SPIN method, the concept and the practice remained embedded in the project. One reason SPIN-Farming was initially identified as a plausible method for carrying out this pilot was the flexibility it offers in terms of scale and scope. The output, in terms of produce and financial gain, can be scaled up or down depending on the circumstances and goals of the practitioners. In order to scale up the economic viability of the project, while also enhancing other aspects of the project, the organizers identified the following changes and improvements: 
- Merge and extend SPIN training and preparation for the growing season over a longer period of time during the winter in order to engage the seniors more fully in the preparatory phase and minimize the gap between the training and preparation phase and implementation phase;

- During the preparatory phase, involve the seniors in identifying short- and longerterm crops to be grown and in mapping out the planting schedule, in order to include their cropping preferences and guarantee adequate and continuous harvest throughout the growing season;

- Secure the land base early enough so that planting-bed preparation and seeding can take place in early spring (with timing dependent on suitable climatic conditions);

- Select production site(s) bearing in mind the pros and cons of single-site versus multisite SPIN operations. For example, multisite operations are more difficult to coordinate than a single-site operation, but can have advantages in terms of accessibility for the seniors, whereas single-site operations can increase the opportunities for intercultural exchange;

- Secure suitable and adequate infrastructure for processing (e.g., washing, bagging) and cold storage;

- Engage the seniors in developing and coordinating a marketing strategy (e.g., farm-gate, restaurants, farmers' markets);

- Expand the program to include younger members of immigrant families, either as volunteers or as members of the social enterprise, and/or English-speaking seniors;

- Invite high-school and university students from community-service learning pro- grams to become involved as volunteers in the project.

Given the growing number of senior immigrants in Canada, there is potential for this type of initiative to be piloted in other communities, and interest in doing so has been expressed by a federal government agency as well as by social economy organizations in two other provinces. However, it is likely that initiatives established in other contexts would unfold differently. One of the SAGE organizers explained, "It won't ever be exactly the same as the Edmonton model, because it will be unique to the time and place and people and cultures that are involved, wherever they are. So, this is an experience we've had that has taken us to a certain point and will continue on its journey."

This research was limited to the first year of a pilot project due to availability of funding. A more indepth assessment of the economic, social, and health impacts of this project could be carried out in a longitudinal study; there are plans to pursue this in the coming year in partnership with a broader range of subject specialists. The results of the research to date suggest that involvement in commercial urban agriculture can contribute to the adaptation and integration of senior immigrants into Canadian society, and contribute to participating seniors' overall health and well-being. Urban agriculture in general, and SPIN-Farming in particular, create opportunities to generate and integrate a broad range of social, economic, environmental, and health benefits that "transcend the individual and leaves lasting change on others and on the physical and social space of the community" (Bellows et al., 2003, p. 5). The positive impacts of this pilot project have resulted in "Urban Farming for Senior Immigrants" becoming a permanent program at SAGE; in 2009 the city of Edmonton granted long-term land tenure for the program at a centrally located community garden in downtown Edmonton.

\section{Acknowledgements}

The authors would like to acknowledge and thank the following individuals and agencies who made this pilot project and research possible: the senior 
immigrants who took part; Wally Satzewich and Gail Vandersteen of SPIN-Farming; Maureen Elhatton for coordinating this project; the $\mathrm{MCHB}$ for providing vital links to ethnic communities and interpretation for the seniors; SAGE for their vision and ongoing support; and Dr. Kyle Whitfield and Dr. Fay Fletcher for their valuable input on this research. The pilot year of this project would not have been possible without the support of the Catherine Donnelly Foundation, the city of Edmonton, and the Faculty of Extension at the University of Alberta.

\section{References}

Bellows, A. C., Brown, K., \& J. Smit. (2003). Health benefits of urban agriculture. Venice, CA: Community Food Security Coalition. Retrieved from http:// foodsecurity.org/UAHealthArticle.pdf

Brown, V. M., Allen, A. C., Dwozan, M., Mercer, I., \& Warren, K. (2004). Indoor gardening and older adults: Effects on socialization, activities of daily living, and loneliness. Journal of Gerontological Nursing, 30, 34-42.

Charmaz, K. (2000). Grounded theory: Objectivist and constructivist methods. In N. K. Denzin \& Y. S. Lincoln (Eds.), Handbook of qualitative research (pp. 509-535). Thousand Oaks, NY: SAGE Publications.

Cosgrove, S. (2010). Montreal's community gardening program. Canada's Office of Urban Agriculture. Retrieved from http://www.cityfarmer.org/ Montreal13.html

Durst, D. (2005). Aging amongst immigrants in Canada: Policy and planning implications. Paper presented at the meeting of the $12^{\text {th }}$ Biennial Canadian Social Welfare Policy Conference on Forging Social Futures, June 17, 2005. Retrieved from http://www.ccsd.ca/cswp/2005/durst.pdf

Durst, D., Abu-Laban, S., MacLean, M., Ng, C., \& Northcott, H. (2001). The integration experiences of immigrant seniors. University of Regina, Social Policy Research Unit. Retrieved from http:/ cat. uregina.ca/spr/assets/documents/writeup.pdf

Hanna, A. K., \& Oh, P. (2000). Rethinking urban poverty: A look at community gardens. Bulletin of Science, Technology and Society, 20, 207-216. doi: $10.1177 / 027046760002000308$

Milligan, C., Gatrell, A., \& Bingley, A. (2004). Cultivating health: Therapeutic landscapes and older people living in Northern England. Social Science and Medicine, 58, 1781-1793. doi:10.1016/S0277-9536(03)00397-6

Mougeot, L. J. A. (2006). Growing better cities: Urban agriculture for sustainable development. Ottawa, Canada: International Development Research Centre (IDRC).

Patel, I. C. (1991) Gardening's socio-economic impacts. Journal of Extension 29(4). Retrieved from http://www.joe.org/joe/1991winter/a1.html

Public Health Agency of Canada. (2010). Social determinants of health. Retrieved from http://www.phac-aspc.gc.ca/ph-sp/ determinants/index-eng.php

Raphael, D. (Ed.). (2004). Social determinants of health: Canadian perspectives. Toronto, Ontario: Canadian Scholar's Press Inc.

Rajwani, S. (2009, August 27). Extension faculty council orientation. Faculty of Extension, University of Alberta. Retrieved from http://www3.extension. ualberta.ca/faculty/orientation.pdf

Redwood, M. (2009). Agriculture in urban planning: Generating livelihoods and food security. Ottawa, Ontario: International Development Research Centre.

Satzewich, W., \& Christensen. R. (2005). SPINFarming $^{\mathbb{R}}$ : How to Grow Commercially on Under an Acre. Self-published.

Service Canada. (2010). A reference guide to old age security and Canada pension plans. Retrieved from http://www.servicecanada.gc.ca/eng/isp/pub/ove rview/refguide6.shtml

Statistics Canada. (2006). A portrait of seniors in Canada: Chapter 7. Immigrant seniors. Retrieved from http://www.statcan.ca/english/freepub/89519-XIE/2006001/immigrant.htm

Stebbins, R. (2001). Exploratory research in the social sciences. Qualitative Research Methods Series 48. London: SAGE Publications.

Strauss, A., \& Corbin, J. (1998). Basics of qualitative research: Techniques and procedures for developing grounded theory. London: SAGE Publications.

UN-Habitat. (2004). State of the world's cities 2004/ 2005. Retrieved from http://ww2.unhabitat.org/ mediacentre/sowckit.asp

Urban Partners. (2007). Farming in Philadelphia: Feasibility analysis and next steps. A report prepared for: Institute for Innovations in Local 
Farming. Retrieved from http://www.spin farming.com

Valtonen, K. (2004). From the margin to the mainstream: Conceptualizing refugee settlement processes. Journal of Refugee Studies, 17: 70-96. doi:10.1093/irs/17.1.70

Yin, Robert. (2009). Case study research design and methods. $4^{\text {th }}$ edition. Applied Social Research Methods Series. Vol. 5. London: SAGE

Publications. 
Journal of Agriculture, Food Systems, and Community Development ISSN: 2152-0801 online www.AgDevJournal.com 